\title{
ESPAÇOS DE NEGROS E BRANCOS EM LIVROS DIDÁTICOS DE GEOGRAFIA DO ESTADO DO PARANÁ, BRASIL
}

\section{The place of blacks and whites in textbooks of Geography of Paraná State, Brazil}

Wellington Oliveira dos Santos ${ }^{1}$

Resumo: Este trabalho analisa formas discursivas que operam nos livros didáticos de Geografia do Paraná aprovados para o Programa Nacional do Livro Didático de 2007 (PNLD/2007). O objetivo é discutir formas de hierarquização entre os grupos raciais brancos e negros que podem atuar de modo a manter ou criar relações de dominação entre os grupos raciais, de acordo com o conceito de ideologia proposto por John B. Thompson. Os livros didáticos analisados pouco apresentam personagens negros, e estabelecem o branco como padrão de humanidade e ocupante do território paranaense; ao mesmo tempo em que "racializam" o negro e diminuem a presença da população negra no estado do Paraná. As vinhetas dos livros, relacionadas à construção cientifica do saber, não apresentam personagens negros, o que indica que esses estão distantes de serem considerados capazes de fazer parte da construção do saber científico ocidental do qual a Geografia faz parte.

Palavras-chave: Relações raciais. Livro didático. Ensino de geografia. Paraná (Estado).

\begin{abstract}
This paper examines discursive forms that operate in the textbooks of Geography of Paraná approved by the Programa Nacional do Livro Didático 2007 (PNLD/2007). The goal is to discuss ways to rank representation of white and black racial groups that acts to maintain or create relationships of domination between racial groups, according the concept of ideology proposed by John B. Thompson. The textbooks analyzed show few black characters, and set the standard of white as humanity and the occupier of the territory of Paraná, at the same time they racialize black characters and decrease the visibility of the black population in the state of Paraná. The vignettes of books related to the construction of scientific knowledge, have no black characters, indicating that these are far from being considered able to be part of the construction of scientific knowledge of which Western geography is a part.
\end{abstract}

Keywords: Race relations. Textbook. Geography teaching. Paraná (State).

\footnotetext{
${ }^{1}$ Universidade Federal do Paraná (UFPR), Núcleo de Estudos Afro-brasileiros, Rua Quinze de Novembro, 1299, Centro, CEP 80060-000, Curitiba, PR, Brasil. E-mail: psicologowell@gmail.com
} 


\section{Introdução}

Neste texto temos como foco a análise da presença de personagens negros e brancos em ilustrações dos livros de Geografia regionais do Paraná para o Ensino Fundamental aprovados no Programa Nacional do Livro Didático de 2007 (PNLD/2007). A proposta é discutir, a partir dos dados da pesquisa, formas de hierarquização entre os grupos raciais que podem atuar de maneira ideológica, isto é, de modo a manter ou criar relações de dominação entre os grupos raciais. $\mathrm{Na}$ análise dos dados, utilizamos, sobretudo, algumas das categorias de análise da ideologia propostas por J. B. Thompson (1995).

Consideramos os livros didáticos formas simbólicas que podem ser relacionadas a outras, tais como a literatura, mas não deixamos de lado suas particularidades. Entre elas, damos destaque ao discurso de ciência/verdade que acompanha esses livros; discurso esse que também resulta da concepção dos livros didáticos como manuais de ensino de disciplinas aos estudantes. Como argumenta Apple (1995), o livro didático frequentemente define a cultura legítima ${ }^{2}$ a ser transmitida, estabelecendo grande parte das condições de ensino e aprendizagem em muitos países. Por essa razão, ele é objeto de estudo e reflexão de pesquisadores, movimentos sociais e do próprio Estado no que se refere ao combate a desigualdades socialmente construídas.

A permanência das desigualdades entre negros e brancos no Brasil costuma ser justificada como consequência direta da escravidão. Silva (2005) diz que tal argumento desconsidera as oportunidades de ascensão social após a Abolição (ou mesmo antes, pois a maior parte dos negros já era livre antes da Lei Áurea) e ao racismo dirigido aos negros. Santos (1984) afirma que culpar a escravidão pelo fracasso dos negros em competir na sociedade moderna é uma espécie de estratégia para desviar a atenção do que mantém as desigualdades atuais, apontando para um passado que não pode ser alterado. Parte das desigualdades existentes é consequência de práticas sociais que privilegiam o grupo branco, desprezando a existência do negro (e do indígena) na sociedade brasileira.

O racismo no Brasil é interpretado, neste texto, como baseado, sobretudo, nos traços físicos das pessoas, como: cor de pele, formato do nariz, textura do cabelo. Tal racismo pode ser considerado um racismo de status, que privilegia os traços brancos em detrimento dos traços negros (GUIMARÃES, 1997), ainda que, em determinadas esferas da sociedade, negros e brancos convivam em igualdade, o que indica que as relações entre grupos raciais no Brasil podem ocorrer de maneiras horizontais (sem hierarquias) ou verticais (com hierarquias) (TELLES, 2003). As relações verticais tendem a considerar os traços físicos como marcadores de privilégios, e, no racismo brasileiro, os traços físicos são usados para competir por bens materiais e simbólicos, ou seja, o racismo tende a se manifestar abertamente em espaços de competição (SANTOS, 1984).

Além disso, existem lugares em que as relações entre negros e brancos seriam horizontais (isto é, de interação social entre iguais) e lugares onde as relações seriam verticais (isto

\footnotetext{
${ }^{2}$ A cultura que tende a ser considerada a legítima é aquela dos grupos dominantes. De acordo com Apple (1995, p. 84), “[...] a escolha de conteúdos particulares e das formas como devem ser abordados na escola está relacionada tanto com as relações de dominação existentes quanto com as lutas para alterar essas relações."
} 
é, baseadas em hierarquia, onde os traços brancos seriam privilegiados) (TELLES, 2003). Ainda que existam espaços de relações horizontais entre negros e brancos no Brasil, a diferença racial é evocada em detrimento dos negros em momentos onde está em jogo o acesso às riquezas que a sociedade produz (SANTOS, 2007). Isso pode explicar, em parte, dados que apontam diferenças de acesso entre negros e brancos na educação, no mercado de trabalho e no acesso a bens materiais (PAIXÃO; CARVANO, 2008). No racismo brasileiro, as características fenotípicas dos indivíduos negros os deixam em desvantagem em relação aos indivíduos brancos em determinadas esferas de poder (GUIMARÃES, 1997) (tais desvantagens também podem ser acrescentadas às desvantagens de classe e gênero).

A desvantagem baseada em traços físicos pode impedir não apenas o acesso de brasileiros pretos e pardos a bens materiais, mas, também, a bens simbólicos. No caso dos livros didáticos, pesquisas têm mostrado a ausência ou sub-representação dos negros nesses (ROSEMBERG; BAZILLI; SILVA, 2003). Por essa razão, o Estado brasileiro, comprador do livro didático via PNLD, é cobrado pelos grupos sociais para que uma representação justa dos grupos raciais seja feita.

O Estado brasileiro adquire livros didáticos, a serem distribuídos na rede pública, de diversas editoras. As obras das editoras somente são compradas se passarem pela avaliação dos livros didáticos. Graças à avaliação, a qualidade dos livros didáticos tem melhorado nos últimos anos (MANTOVANI, 2009). Como o Estado gasta muitos recursos financeiros com a compra de livro didático, as editoras parecem se esforçar para se adequarem às avaliações do Ministério da Educação (MEC). A recomendação dos livros didáticos pelo MEC é feita por uma comissão de especialistas, professores universitários que avaliam os livros tentando excluir aqueles que trazem formas explícitas de racismo e qualquer tipo de discriminação de sexo ou religião, por exemplo, mas que, geralmente, não atentam para formas implícitas de hierarquização entre os grupos sociais presentes nos livros (SILVA, 2005). De acordo com Peres (2002), a vigilância exercida pelo Estado com o PNLD é um risco e uma necessidade. Risco porque o PNLD pode servir a interesses de governos, aprovando livros didáticos que, por exemplo, apoiam determinados grupos. Por outro lado, o PNLD é uma necessidade porque, sem ele, muitas das práticas preconceituosas e equívocos históricos continuariam a ser apresentados. Peres (2002) argumenta que, para manter o ideal democrático de nossa sociedade, a vigilância do livro didático não é (e não deve ser) monopólio do Estado. É necessário que a sociedade esteja vigilante acerca do conteúdo dos livros e como está sendo feita a avaliação desses livros - ou seja, vigiar os livros e o vigia desses.

Entre os critérios de eliminação dos livros didáticos encaminhados pelas editoras, o PNLD de 2007, para livros de $1^{\mathrm{a}}$ a $4^{\mathrm{a}}$ série de Geografia, apresentou:

O livro didático não pode expressar preconceitos de origem, etnia, gênero, religião, ideologia, idade ou quaisquer outras formas de discriminação. Não só os textos, mas também as representações gráficas, como fotos, mapas, tabelas, quadros ou outros tipos de ilustração necessários para compreender os conteúdos geográficos devem ser isentos de preconceitos e de propaganda. (BRASIL, 2006, p. 13, grifo do autor) 
Tais critérios de exclusão são necessários e respeitam a Constituição de 1988. Ainda assim, esse critério eliminatório parece não dar conta de formas de preconceito implícitas que possam estar presentes nos conteúdos dos livros didáticos. As peculiaridades do racismo brasileiro tendem a não ser percebidas na avaliação dos livros didáticos. No caso dos professores das escolas públicas, geralmente, eles apenas participam do processo de escolha dos livros já recomendados pelos avaliadores. Sabendo disso, as editoras, além de excluírem qualquer conteúdo explicitamente preconceituoso de seus livros, utilizam estratégias para conseguir a adesão dos professores aos seus livros recomendados (MANTOVANI, 2009).

O combate ao racismo nos livros didáticos está relacionado a estudos que denunciaram a existência de formas explícitas e implícitas de racismo nas obras. Juntamente com essas denúncias, outras foram feitas por ativistas do movimento negro e pesquisadores quanto à presença da população negra no campo educacional brasileiro, notadamente no currículo. A alteração feita na Lei de Diretrizes e Bases da educação (LBD), com a Lei $10.639^{3} \mathrm{em}$ 2003, que inclui o ensino de História e Cultura Afro-brasileira no currículo do Ensino Básico, foi uma grande conquista para o combate ao racismo. A modificação da LDB, com a Lei 10.639/ 03, teve desdobramentos na política dos livros didáticos brasileiros: a partir do edital do PNLD de 2005, ficou estabelecido que os livros didáticos também devem observar a Lei 10.639/03 (PAIXÃO et al., 2010).

Rosemberg, Bazilli e Silva (2003) apontam que os estudos acerca do racismo em livros didáticos foram exclusivamente voltados para negros ou indígenas. As pesquisas focalizaram, sobretudo, os livros de Ensino Fundamental, com privilégio para os livros de História e Língua Portuguesa. Por essa razão, entendemos que pesquisas com livros didáticos de Geografia e outras disciplinas relacionadas às ciências naturais são importantes para o campo de estudo do racismo em livros didáticos, especialmente se tal denúncia levar em consideração as posições ocupadas não apenas por negros, mas, também, por brancos nesses livros.

Entendemos que a Geografia trata de estudar o território, o espaço, descobrindo o outro que ocupa esse espaço. Geografia é conhecimento do espaço para agir sobre o espaço, entendendo que esse espaço já tem ação humana (SANTOS, 2007). Nesse sentido, importa saber qual o espaço que os livros didáticos apontam ser ocupado por negros e brancos. Importa porque o racismo brasileiro

[...] ao definir clivagens sociais e hierarquizar indivíduos e grupos a partir de seus pertencimentos raciais se expressará na constituição de 'lugares' (nos sentidos espacial e social) onde a presença do desfavorecido será majoritária (lugares de pobreza, da despossessão, da subalternidade) e lugares onde sua presença será minoritária (lugares da riqueza, do poder, do saber socialmente legitimado, etc.): lugares com a marca desta distinção social. (SANTOS, 2007, p. 30)

${ }^{3}$ Em 2008, a Lei seria alterada pela Lei 11.645/2008, incluindo História e Cultura Indígena. 
Espaços de negros e brancos em livros ...

A construção de lugares espaciais e sociais - no caso dos livros didáticos de Geografia do Paraná - nos remete à própria construção do imaginário social sobre a população que ocupa o território paranaense. Segundo Santos (2007), esse imaginário social privilegia a colonização europeia, ocultando a presença dos negros, apagando a escravidão da história da região e autorizando violências diversas.

\section{O negro nos livros didáticos e livros didáticos de Geografia}

Em revisão de literatura sobre racismo em livros didáticos e seu combate no Brasil, nas cinco últimas décadas do século XX, Rosemberg, Bazilli e Silva (2003) constataram que os resultados dos estudos com livros didáticos, que tiveram como marco o estudo de Dante Moreira Leite (2008) nos anos 1950, já captavam a manifestação de formas de preconceito racial não explicitadas, como a não-apresentação do negro na sociedade e/ou sua representação em situação socialmente inferior ${ }^{4}$.

Nos anos de 1970 e de 1980, as pesquisas, em geral, indicavam: a naturalização e universalização da condição de ser branco, pois sua condição racial geralmente não era explicitada e aparecia com mais frequência nas capas dos livros; a sub-representação de negros (e indígenas) em textos e ilustrações; negros, adultos e crianças, como coadjuvantes - associação à subalternidade; sub-representação de alunos e professores negros; e associação do negro à animalidade (ROSEMBERG; BAZILLI; SILVA, 2003).

As produções mais recentes (décadas de 1980 e de 1990) apontavam algumas mudanças, como: maior humanização da criança negra; ausência de associação entre o negro e animais negros; destaque maior nas ilustrações; e maior diversificação de contextos sociais, familiares e profissionais na representação de negros, além de valoração positiva de traços físicos (ROSEMBERG; BAZILLI; SILVA, 2003). Os pesquisadores apontam a presença de discursos igualitaristas nos livros que conviviam com representações discriminatórias de personagens. Ou seja, ao mesmo tempo em que o tratamento igualitário é evocado pelos livros didáticos, apoiando-se na mestiçagem da população brasileira, personagens negros continuam a ocupar menos posições de destaque, sendo, portanto, tratados de maneira desigual; personagens brancos ainda tendem a ser usados como referência de humanidade (o próprio público leitor suposto tende a ser branco); a Europa ainda é tomada como referência de civilização e humanidade.

Algumas pesquisas com livros didáticos de Geografia evidenciam a existência/permanência de diversas formas de hierarquização racial entre negros e brancos. Por exemplo, Tonini (2001) apresentou estudo com livros didáticos de Geografia de $7^{\mathrm{a}}$ e $8^{\mathrm{a}}$ séries do Ensino Fundamental. Entendendo que os livros didáticos assumem discursos de verdade (ciência) sobre etnias e continentes, a autora argumenta, entre outras coisas, que os livros de Geografia

\footnotetext{
${ }^{4}$ Leite (2008) destacou que os/as negros/as apareciam somente em situações subalternas, como empregados. Afirmou que "[...] a maneira de ver a posição das raças [inferiores e superiores] se traduz pelo lugar destinado aos negros no mundo social" (LEITE, 2008, p. 220, grifo do autor).
} 
analisados colocam as identidades étnicas distintas da identidade da Europa/Estados Unidos como subalternas, hierarquizando os povos. As etnias tendiam a ser apresentadas "coladas" com os continentes. Quando os textos falavam da composição da América Latina, apontavam para a diversidade de etnias que aqui chegaram, com ênfase nos negros, mas não faziam o mesmo ao tratar da Europa. Seria como se a existência de certa pureza racial justificasse a supremacia da Europa sobre o resto do mundo, e a cor de pele seria um marcador. Enquanto os europeus e americanos aparecem em contextos de tecnologia e urbanização, os asiáticos e africanos aparecem em contextos de pobreza ou com atividades manuais (TONINI, 2001).

Além disso, as representações do negro podem estar relacionadas a pobreza e desqualificação. Na pesquisa de Costa e Dutra (2009) sobre representação dos negros e da África, em uma coleção de livros didáticos para as séries finais do Ensino Fundamental aprovada no PNLD/2008, negros e moradores do continente africano tenderam a aparecer em posições de baixo status, muitas vezes no mercado informal. No livro dedicado à formação da sociedade brasileira ( $6^{a}$ série), a contribuição do negro foi reduzida ao plano cultural, com a capoeira e as religiões de matriz africana. Para Costa e Dutra (2009), isso seria uma forma de mistificação e folclorização da cultura negra. Em um dos livros, havia comparações entre moradias de continentes distintos. Moradias africanas, representadas por construções simples em aldeias, eram comparadas com construções dos países desenvolvidos.

Por outro lado, Costa e Dutra (2009) verificaram que o discurso em relação à África do Sul e ao Egito continha certas particularidades em relação a outros países do continente africano. Em alguns momentos, a presença branca era destacada nesses países, e a Cidade do Cabo foi comparada às cidades europeias em termos de Índice de Desenvolvimento Humano (IDH). Ainda assim, a África do Sul, no geral, não foi vista como igual diante dos países europeus (COSTA; DUTRA, 2009). Com relação ao Egito, os autores interpretaram que a presença de brancos nas representações desse país seria uma tentativa de embranquecimento para afastá-lo do continente africano.

Em relação aos livros de $7^{a}$ série, a presença de negros diminuiu. Segundo Costa e Dutra (2009), isso provavelmente estaria ligado ao fato de esse livro ser mais tecnicista do que os outros da coleção, voltado à Geografia física. Os autores apontam que isso pode estar relacionado à impossibilidade de representação da África no discurso cientifico.

Os resultados da pesquisa de Ratts et al. (2006) - acerca da representação do negro e da África em ilustrações nas duas coleções de livros de Geografia destinados às séries finais do Ensino Fundamental mais utilizados na Rede Municipal de Ensino de Goiânia - coincidem em diversos aspectos com os de Tonini (2001) e Costa e Dutra (2009). Nas coleções, pouca referência a população negra foi encontrada. Quando os negros e a África eram representados, eram em espaços estereotipados. Por exemplo, o caos e a miséria social são apresentados como homogêneos no continente africano. Quanto às práticas religiosas africanas, essas foram tratadas como fetichistas ou animistas. A origem do comércio de negros como escravos foi atribuída, pelos livros, aos próprios negros africanos e sua estrutura social, que, em lutas internas entre grupos étnicos, escravizavam uns aos outros. A participação de europeus ou outros povos no tráfico negreiro foi desconsiderada. A África urbanizada não apareceu nas coleções. Não foi apresentada uma diversidade social e espacial do continente (RATTS et al., 2006). As coleções não falavam sobre as formas de sociedades da África antes do colonialismo. Também não falavam das resistências do negro no Brasil, como os quilombos. 
Espaços de negros e brancos em livros ...

No estereótipo "negros como pobres e miseráveis", para Ratts et al. (2006), o problema não é a apresentação dos negros nesses campos, considerando a participação da população negra entre os mais pobres, mas, sim, a excessiva apresentação dessas imagens, ligando o negro à pobreza. As causas da pobreza da população negra não são discutidas pelas coleções. Frequentemente, negros apareceram em espaços sociais inferiores: persistência das práticas do regime escravista, que colocava negros em serviços braçais. Também observaram o que descreveram como fixação do negro em espaços de serviço braçal. No caso da retratação do negro como escravo, os autores argumentam que é preciso uma maior discussão dessas imagens de negros como escravos, especialmente em livros onde estão ausentes de representações positivas.

Inspirados em Silva (2003 apud RATTS et al., 2006), Ratts et al. (2006) propõem que a apresentação de negros como jogadores de futebol, dançarinos e cantores, nos livros analisados, é um "falso status social positivo". Falso porque como os negros tendem a aparecer mais nesses papéis valorizados do que em outros da sociedade, pode favorecer uma naturalização da raça negra nesses papéis, mais relacionados à emoção, força física e sensualidade - ou seja, papéis mais relacionados ao instintual. Uma das exceções aos estereótipos foi a ilustração do ex-presidente da África do Sul Nelson Mandela, símbolo da luta antirracista dos negros daquele país e internacionalmente.

Por sua vez, Rodrigues e Cardoso (2010) apresentaram pesquisa na qual analisaram livros de História e Geografia com a temática representação dos negros nos livros didáticos e a Lei 10.639/03, que trata do ensino de História e Cultura Afro-brasileira. Analisaram um livro de Geografia de $6^{a}$ série, de 2003, anterior à Lei 10.639/03, e um de $8^{a}$ série, posterior à referida lei, de 2007. Encontraram inúmeros estereótipos nos dois livros analisados, relacionando o negro à passividade e à inferioridade, o que consideram grave, já que a Geografia tem um importante papel na temática afro-brasileira, notadamente na análise de diferentes territórios e grupos étnicos ao redor do globo. Via de regra, as fotografias apresentadas nos livros sobre a África traziam personagens negros em situações de pobreza. O livro, editado antes da Lei 10.639/03, abordava temas relacionados à população negra no Brasil de maneira folclorizada, a partir do olhar do europeu. Poucas vezes, os livros apresentaram visões positivas do continente africano, mesmo no caso do livro posterior à Lei 10.639/03, que, ao tratar do continente africano em diversos aspectos, acabou dando muita ênfase à pobreza e o elevado número de pessoas soropositivas no continente. Para os pesquisadores, esse problema de estereótipos pode resultar em reprodução de estereótipos acerca da população negra em sala de aula, sobretudo quando associado ao pouco conhecimento acerca da Lei 10.639/03 dos professores (RODRIGUES; CARDOSO, 2010).

Em nossa opinião, uma crítica que pode ser feita às pesquisas com livros de Geografia aqui apresentadas é que elas tendem a focalizar, em demasia, os personagens negros, e acabam deixando de lado um estudo mais detalhado de como os brancos são tratados pelos livros didáticos. Isso pode ser visto já nos objetivos de muitas das pesquisas: apresentar como o negro, a África ou ambos são representados pelos livros de Geografia. Acreditamos que, de certa forma, isso não apenas resulta da naturalização do branco como modelo de normalidade, mas, também, ajuda a manter essa situação. 


\section{Metodologia}

Em nossa metodologia, analisamos as ilustrações presentes nas obras Aprendendo a geografia do Paraná (BLEY, 2004), e Paraná: sua gente e suas paisagens (FERRETTI; PAZZINATO; RENK, 2004). Optamos pelas obras porque foram as duas recomendadas pelo PNLD/2007 para Geografia do estado do Paraná. Utilizamos procedimentos de análise de conteúdo (BARDIN, 1985) para análise preliminar das ilustrações. A partir de categorias predeterminadas de análise, contamos os personagens presentes em todas as ilustrações dos livros. Por personagem, entendemos todos os corpos humanos ou seres antropoformizados presentes nas ilustrações. Utilizamos o programa computacional Statistical package for social sciences (SPSS, 2008) para organização e análise dos dados, a partir da codificação dos atributos de cada personagem contado. Nossa ênfase não foi o conteúdo didático do livro, e sim as personagens que ele utiliza para apresentar esse conteúdo. Como na maioria das vezes quem escolhe as ilustrações dos livros didáticos não são os autores, e sim a editora, por meio de ilustradores (RATTS et al., 2006), consideramos relevante apontar como negros e brancos são apresentados.

Para uma interpretação dos espaços ocupados por negros e brancos nos livros de Geografia do Paraná, utilizamos o conceito de ideologia ${ }^{5}$ de Thompson. Para Thompson (1995), formas simbólicas, em uma sociedade de comunicação de massa, podem ser usadas para manter e sustentar relações de dominação entre indivíduos ou grupos de indivíduos. Nesse caso, essas formas simbólicas estariam atuando de maneira ideológica ou, em outras palavras, a serviço do poder. Poder, aqui, é acesso a bens materiais e simbólicos. Formas simbólicas são falas, ações, imagens, sons, escritas etc., que são produzidos por sujeitos e reconhecidos por eles e outros como construtos significativos (THOMPSON, 1995). Quando discute o papel das formas simbólicas nas sociedades contemporâneas, Thompson (1995) está interessado em como elas podem atuar de maneira ideológica; isto é, servindo em circunstâncias sócio-históricas específicas para estabelecer e sustentar relações de dominação. Relações de dominação não se restringem ou se submetem às relações do capitalismo: as desigualdades assimétricas podem ser baseadas em critérios raciais, sexuais, culturais, entre outros. Neste texto, temos como foco a discussão de desigualdades entre grupos raciais no contexto brasileiro.

Thompson (1995) apresenta alguns modos de operação da ideologia; modos como o sentido pode servir para estabelecer e sustentar relações de dominação em contextos sóciohistóricos específicos. Aqui destacamos os cinco modos gerais de operação da ideologia e algumas de suas estratégias típicas ${ }^{6}$ legitimação (narrativização e racionalização), dissimulação, unificação (simbolização da unidade), fragmentação (diferenciação) e reificação (naturalização e passivização). Esses modos não são os únicos modos que a ideologia pode operar, e nem sempre operam independentemente um do outro. Circunstâncias concretas é que indicam os usos ideológicos das formas simbólicas (fenômenos simbólicos não são ideológicos como tais, o

\footnotetext{
${ }^{5}$ Discussão mais profunda do uso do termo ideologia nas ciências humanas pode ser encontrada em Thompson (1995).

${ }^{6}$ Destacamos, em negrito, os modos gerais de operação da ideologia, e, em itálico, as estratégias relacionadas a esses modos.
} 
Espaços de negros e brancos em livros ...

que descarta um uso neutro do conceito de ideologia). Quando discutimos os resultados da pesquisa, apresentamos uma breve descrição dos modos gerais de operação da ideologia e de algumas estratégias típicas de construção simbólica que podem atuar mantendo as desigualdades raciais entre negros e brancos no racismo brasileiro.

\section{Negros e brancos em livros didáticos de Geografia do Paraná}

No PNLD/2007 Geografia, dois livros foram indicados para geografia do Paraná: Aprendendo a geografia do Paraná e Paraná: sua gente e suas paisagens. O primeiro livro é da autora Berenice Bley (2004) e, na época, era destinado à $3^{a}$ série do Ensino Fundamental. O segundo livro é de autoria de Eliane Ferretti, Kátia Pazzinato e Valquíria Renk (2004). Eles abordam temas em comum, como as paisagens naturais e sociais paranaenses, a formação do povo do Paraná, o espaço urbano e o espaço rural do estado do Paraná.

O Guia dos livros didáticos de Geografia traz informações pertinentes ao modo como os dois livros tratam do item construção da cidadania (BRASIL, 2006). No caso do livro Aprendendo a geografia do Paraná, o guia adverte que "Não são mostradas plenamente as diversidades étnicas, de gênero e cultural presentes na sociedade paranaense, que poderiam ser exploradas para se estimular a construção da cidadania" (BRASIL, 2006, p. 280).

O Guia do Livro Didático não faz críticas negativas ao tema da diversidade no livro Paraná: sua gente e suas paisagens. Pelo contrário, o elogia na abordagem da diversidade, afirmando que ele propõe

[...] leituras e reflexões sobre a realidade social, notadamente no desen-
volvimento dos assuntos ligados às populações afro-descendentes, in-
dígenas e de imigrantes, buscando-se a valorização dos aspectos cultu-
rais e evitando-se formas de discriminação racial e social. (BRASIL,
2006, p. 296)

Ao ler apenas a resenha do livro, poderíamos esperar que esse livro contemplasse, de maneira positiva, as diferentes etnias que compõem o estado paranaense. Como apresentamos nos resultados de nosso estudo, isso ocorreu, mas de maneira ambígua.

Contamos 461 personagens em 251 unidades de informação. Unidades de informação são os contextos em que os personagens foram encontrados. A contagem de personagens nas unidades de informação seguiu o seguinte critério: caso a unidade de informação apresentasse mais de sete personagens, em que nenhum deles se destacava, esses eram tomados como apenas um personagem (que chamamos de personagem grupo). No caso da análise por coretnia, quando esse personagem grupo trazia personagens de cores distintas, era classificado de grupo multiétnico.

De acordo com a cor/etnia dos personagens, dos 461 personagens contados, 333 eram $(72,2 \%)$ brancos, dez $(2,2 \%)$ pretos, nove $(2 \%)$ pardos, $15(3,3 \%)$ indígenas, $46(10 \%)$ amarelos, 15 (3,3\%) grupos multiétnicos e 33 (7,2\%) fenotipicamente indeterminados. Como o nosso foco são personagens brancos e pretos e pardos (negros), a partir desse ponto, apresentaremos resultados relativos a esses grupos raciais e, também, ao grupo multiétnico. Dividindo o número de personagens brancos pelo número de personagens negros (pretos e par- 
dos), temos uma taxa de branquidade (SILVA, 2005) de 17,5 personagens brancos para cada personagem negro.

Tonini (2001) argumenta que os livros didáticos assumem discursos de verdade sobre as etnias. Se esse for o caso, um discurso de verdade sobre os negros, de acordo com as ilustrações dos livros de geografia do Paraná, é que eles são percentualmente poucos na população do estado, portanto, pouco aparecem nas ilustrações. Comparando com dados populacionais, isso está longe de ser "verdade": a população de pretos e pardos do Paraná está em torno de 25\% (PESQUISA..., 2007). O que parece ocorrer nas representações raciais das ilustrações dos livros didáticos é o que Giroux (1999) chamou de branquidade como padrão de humanidade. A taxa de branquidade indica que os brancos são tomados como representantes da população paranaense, reservando, ao negro e aos outros grupos raciais, o espaço do outro.

O livro Aprendendo a geografia do Paraná apresentou 259 personagens, sendo 217 personagens brancos $(83,8 \%)$ e nove $(3,5 \%)$ negros. Quanto ao grupo multiétnico, 7 (2,7\%) personagens entraram nessa categoria. Taxa de branquidade de 24,1 personagens brancos para cada personagem negro. O livro Paraná: sua gente e suas paisagens apresentou 202 personagens, sendo $116(57,4 \%)$ brancos, dez (5\%) negros e $8(4 \%)$ grupos multiétnicos. Taxa de branquidade de 11,6 personagens brancos para cada personagem negro.

Comparando os dois livros, verificamos que um aumento do número de personagens nas ilustrações não significa um aumento no número de personagens negros, proporcionalmente: o livro Aprendendo a geografia do Paraná apresentou 259 personagens e uma taxa de branquidade de 24,1; o livro Paraná: sua gente e suas paisagens apresentou 202 personagens, com uma taxa de branquidade de 11,6 personagens brancos para cada personagem negro. Essa maior desigualdade entre negros e brancos no livro Aprendendo a geografia do Paraná provavelmente se relaciona ao alerta feito pelo próprio Guia do Livro Didático. Se considerarmos negros e brancos camadas sociais, podemos dizer que o livro Aprendendo a geografia do Paraná privilegia uma camada social (branca) em relação a outra (negra).

Como apresentamos, o Guia do Livro Didático elogia a apresentação da diversidade racial no estado do Paraná feita pelo livro Paraná: sua gente e suas paisagens, quando esse trata de assuntos relacionados a negros e indígenas. Apesar da taxa de branquidade do livro ser menor que a do livro discutido anteriormente, perguntamos que tipo de construção da cidadania o Guia está indicando e onde está o espaço para os assuntos ligados às populações afrodescendentes. Aqui apresentamos um exemplo: ao tratar das diferentes etnias que fazem parte da constituição do povo paranaense, o livro traz textos comentando acerca dos povos indígenas e dos imigrantes. No caso da população "afro-brasileira", o livro traz um texto externo (de fonte secundária) para tratar da questão. O texto alerta para a persistência de desigualdades para o acesso da população a determinados serviços, argumentando que, mesmo com o final da escravidão, pouco mudou em relação à população negra. Ainda assim, contribui para colocar o negro como o outro, como a exceção da sociedade paranaense. Faz isso quando não apresenta um personagem negro na ilustração que acompanha o texto: quem acompanha é uma menina branca em uma vinheta ${ }^{7}$. Faz isso porque os únicos grupos racialmente marcados são

\footnotetext{
${ }^{7}$ Discutimos, adiante, como as vinhetas podem atuar, como esta, de maneira a naturalizar o branco como aquele que representa a investigação científica, ao mesmo tempo em que pode passivizar os negros como objetos a serem estudados.
} 
Espaços de negros e brancos em livros ...

o negro e o indígena - os imigrantes europeus não têm sua cor de pele destacada -, exemplo de fragmentação desses grupos raciais.

Ao tratarem o negro como exceção, os livros didáticos atuam diferenciando esses dos padrões de humanidade expostos nas ilustrações. Tal diferenciação também está relacionada ao espaço ocupado por negros e brancos em relação ao saber científico, como exemplificado pela Figura 1. Enquanto brancos transitaram em diferentes áreas de conhecimento técnico, por exemplo, conduzindo tratores, trabalhando em frigoríficos, os negros, via de regra, foram apresentados (quando foram apresentados) em trabalhos manuais, como no transporte de sacas de café. Tonini (2001) alertava, em seu estudo com livros de Geografia, acerca desse espaço dedicado ao negro no mundo do trabalho, e Santos (2007) fala de como a Geografia pode atuar de modo a manter o racismo ao demarcar lugares para determinados grupos raciais. Provavelmente isso se relaciona com a apresentação do negro como ser humano de baixo status na hierarquia racial brasileira (GUIMARÃES, 1997).

Figura 1. Personagens brancos em espaços de construção de saber científico.

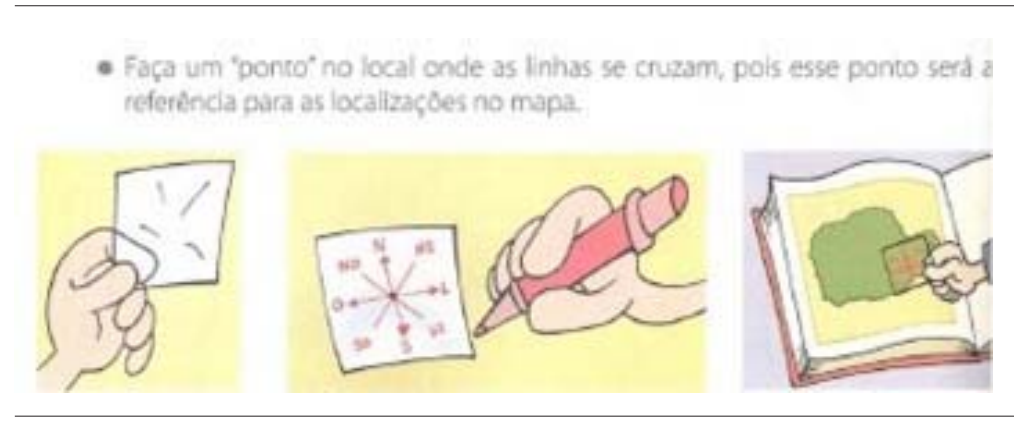

Fonte: Bley (2004, p. 28).

A maior parte dos personagens em ilustrações presentes nos dois livros estava em desenhos. Entretanto, percebemos que, poucas vezes, os negros foram retratados em fotografias. Quando apareciam, a tendência era serem exibidos em uma multidão de personagens, de várias etnias. Boulos Júnior (2008) afirma que o reduzido número de fotografias com negros revela certa dificuldade em mostrá-los no presente. No caso dos livros de História, as pinturas e gravuras servem para colocá-los no passado. Algumas pinturas presentes nas ilustrações dos livros de geografia do Paraná também traziam os negros no passado, em contextos de trabalho manual.

A desvantagem entre negros em brancos foi diferente no caso de homens e mulheres. Dos 307 personagens masculinos, contamos 253 (82,4\%) brancos, 16 (5,2\%) negros e dois $(0,3 \%)$ grupos multiétnicos compostos somente de homens. A taxa de branquidade foi de 15,8 personagens brancos para cada personagem negro. Dos cento e dez personagens femininos, 61 eram (55,5\%) brancas e $3(2,7 \%)$ negras. Taxa de branquidade de 20,3 personagens brancas para cada personagem feminina negra. Quer dizer, se existe um menor número de mulheres nas ilustrações, esse número é ainda menor em relação à mulher negra (a taxa de branquidade 
entre mulheres negras e homens brancos é de 84,3). Provavelmente, isso se relaciona à hierarquia racial brasileira, que trata a mulher negra como ser de baixo status (GUIMARÃES, 1997).

Além da desigualdade de acordo com o sexo, a amostra também revela desigualdade de acordo com a idade dos personagens. Contamos 345 crianças/adolescentes, sendo duzentas e oitenta $(81,2 \%)$ brancas e seis $(1,7 \%)$ negras. Taxa de branquidade de 46,6 personagens brancos para cada personagem negro, o que é revelador de hierarquia racial (GUIMARÃES, 1997), já que a maioria dos personagens da amostra está nessa faixa etária e os livros buscam identificação com seu público leitor. Essa taxa é maior que de toda a amostra $(17,5)$. Contamos 95 adultos, sendo 47 (49,5\%) brancos, 13 (13,7\%) negros e sete (7,4\%) grupos multiétnicos. Contamos três personagens idosos, todos brancos. A taxa de branquidade, no caso adulto, foi de 3,6 personagens brancos para cada personagem negro. No caso dos idosos, isso não pode ser calculado (como não encontramos nenhum personagem negro nessa faixa etária, não podemos dividir o número de personagens brancos pelo número de personagens negros para obtermos a taxa de branquidade).

No livro Paraná: sua gente e suas paisagens, o primeiro personagem visualizado, após a capa, a folha de rosto e uma vinheta, é um personagem negro, na página 11 (Figura 2). Ele aparece convidando os leitores a conhecerem o estado. Na unidade de informação, também encontramos um texto sobre o Paraná, que destaca e exalta as cores da bandeira do estado e algumas das cidades, como Curitiba e Ponta Grossa. O personagem negro, um menino, tem uma mochila nas costas, usa shorts e carrega uma máquina fotográfica pendurada no pescoço, o que indica que ele atuará como turista no estado. A utilização desse personagem negro já no início do livro, em uma atividade valorizada (lazer), pode ser uma estratégia de dissimulação: esconde o fato de que poucos negros aparecem no livro. Também pode indicar um tratamento do negro como o outro na população do estado - ele não é um morador do estado, é um turista, e como tal está apenas de passagem.

Figura 2. Personagem negro em contexto de lazer.

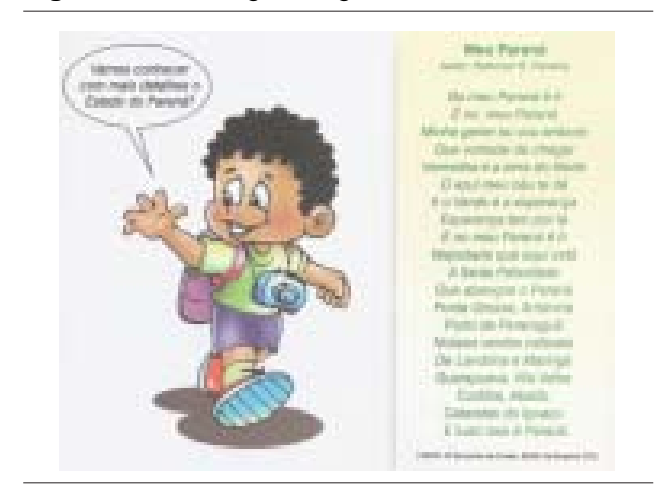

Fonte: Ferretti; Pazzinato; Renk (2004, p. 11).

Fizemos análise das relações de parentesco entre os personagens. Contamos 23 personagens que faziam alguma alusão a parentesco com outro personagem da unidade de infor- 
Espaços de negros e brancos em livros ...

mação, sendo vinte brancos e um personagem grupo multiétnico. Indígenas apareceram dois (pai e filho). A falta de personagens negros em família naturaliza a condição da família branca, predominante, como modelo familiar de nossa sociedade. Muitas vezes, essa família branca se confundia com a familia dos descendentes de imigrantes, o que pode ser considerado uma narrativização ao apresentar imagens de imigrantes como formadores do povo: histórias que contam o passado - de imigração - e tratam o presente - as condições sociais dos descendentes de imigrantes - como uma tradição eterna e aceitável. A Europa desenvolvida tende a ser apresentada sem mistura racial nos livros didáticos, ao contrário de países latino-americanos em desenvolvimento, o que tende a associar o baixo desenvolvimento à miscigenação, segundo Tonini (2001). O imaginário social da construção do povo paranaense, e, também, dos outros estados da região sul do Brasil, aponta para a prevalência da população branca de origem europeia, descendente de imigrantes. O alto grau de desenvolvimento desses estados, comparados aos outros estados do país, muitas vezes os aproxima dos padrões de vida europeus. Geralmente, esse alto grau de desenvolvimento é atribuído ao esforço e saber dos imigrantes. Provavelmente a falta de mistura racial apresentada nos livros didáticos do Paraná contribua para a tese de que o estado somente é desenvolvido por causa da presença branca. Acrescentase a isso o fato de que, enquanto a situação do negro no estado é vista como problemática, o branco é tratado como aquele que conseguiu vencer por seus próprios méritos.

Também realizamos análise das vinhetas dos livros. Vinhetas são ilustrações na forma de tira - semelhante aos quadrinhos encontrados nos jornais impressos - que acompanham seções dos livros. Segundo Boulos Junior (2008), elas buscam certa identificação com o público-alvo dos livros didáticos, tendo, por função, introduzir seções aos leitores; as vinhetas utilizam personagens desenvolvendo determinadas ações, por exemplo, escrevendo em um caderno, indicando aos leitores o que deve ser feito. $\mathrm{Na}$ leitura que realizamos das vinhetas dos livros de Geografia do Paraná, verificamos que os personagens presentes nessas, muitas vezes, realizavam atividades relacionadas à construção de saber ou à investigação científica.

No livro Paraná: sua gente e suas paisagens, encontramos duas vinhetas; no livro Aprendendo a geografia do Paraná, encontramos 12 vinhetas. Apenas personagens brancos, crianças, participam dessas vinhetas, com uma predominância de personagens masculinos (apenas três das vinhetas traziam meninas).

Analisando as vinhetas presentes nos dois livros, a exclusão de personagens negros desses contextos pode ser considerada exemplo de reificação (naturaliz̧ação) da condição branca como portadora do saber e da técnica cientifica, como na vinheta "lendo o mapa" (Figura 3).

Figura 3. Vinheta "lendo o mapa".

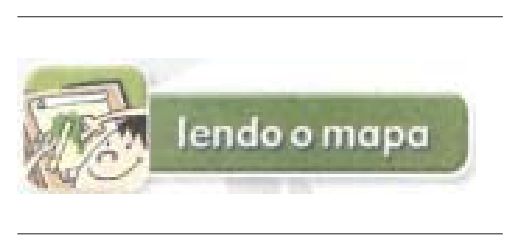

Fonte: Bley (2004, p. 74). 
Como personagens negros não aparecem nas vinhetas, e sim em ilustrações das seções, podemos dizer que são tratados como objetos de estudo - condição reificada de maneira passivizada (são tratados de maneira passiva). Se podemos dizer que "[...] as vinhetas e suas múltiplas expressões vão indicando o que fazer [...] vão, enfim, construindo um tipo-ideal de aluno-leitor que, ao que parece, deve servir de referência para todos os outros" (BOULOS JUNIOR, 2008, p. 84), esse tipo padrão, nos livros de geografia do Paraná aqui analisados, é o aluno branco, majoritariamente masculino. Tal padrão confirma o argumento de Costa e Dutra (2009): o negro e a África estão fora do discurso cientifico, sendo sua contribuição reduzida à cultura folclorizada. As vinhetas dos livros didáticos apontam para o saber científico como saber pertencente ao branco, o que contribui para a manutenção daquilo que Guimarães (1997) chama de hierarquia racial brasileira.

O livro Paraná: sua gente e suas paisagens não utiliza páginas à parte nas aberturas de suas unidades. A capa do livro traz três personagens: duas crianças em um primeiro plano; no segundo plano, há um personagem adulto masculino. A criança em pé, com pincel e palheta de tinta na mão, e boina de pintor, é um menino branco, que é apresentado como se estivesse pintando a paisagem ao fundo em um quadro. Aos seus pés, sentada, está uma menina branca, sorrindo, olhando o que ele está fazendo. O personagem ao fundo é um homem branco, dirigindo um trator perto de alguns animais, em uma espécie de retratação da paisagem rural, que tem mais ao fundo uma barragem, uma cachoeira e um grupo de prédios de uma cidade distante.

Tal apresentação dos personagens pode ser considerada uma fragmentação que segmenta grupos ou indivíduos - no caso, as outras etnias que fazem parte do Paraná. Quem segura o pincel e pinta o quadro, uma forma de arte valorizada, é o menino branco, enquanto a mulher branca, representada pela menina, apenas contempla-o. Não há espaço para negros em algo tão valorizado pela sociedade. Essa apresentação do branco como sendo o capaz de pintar uma obra de arte pode ser uma diferenciação dele dos outros grupos raciais.

O livro Aprendendo a geografia do Paraná, além de personagem na capa, também traz personagens nas capas das unidades. Por exemplo, na abertura da unidade 2, há um menino branco deitado de bruços. Em suas costas há um gato cinza. O menino tem diante de si uma espécie de quebra-cabeça no formato do mapa do Paraná, e ele segura uma das peças. Na capa da unidade 3, há um menino negro de joelhos, diante do mapa do estado do Paraná. O mapa parece ser moldado pelo menino, como se fosse um solo, pois ele está com as duas mãos nele, como se estivesse preparando a terra (Figura 4). Como são seis capas de unidades, cada uma com um personagem, sendo a relação de quatro personagens brancos para um negro (são quatro para um, pois há uma menina amarela na capa da unidade 4), podemos dizer que a taxa de branquidade aqui é menor que no livro como um todo. Em uma primeira leitura, isso é positivo. Mas relacionando com a taxa de branquidade no livro e os espaços ocupados por negros e brancos, podemos dizer que o uso de um personagem negro em uma das aberturas de unidade seja uma dissimulação que desvia a atenção das desigualdades existentes entre personagens negros e brancos e os espaços que ocupam dentro do livro. Pode ser que essa dissimulação tenha contribuído para a avaliação positiva desse livro feita pela comissão do PNLD/ 2007, como explicitado no Guia do Livro Didático (BRASIL, 2006). 
Espaços de negros e brancos em livros ...

Figura 4. Capas das unidades do livro Aprendendo a geografia do Paraná.

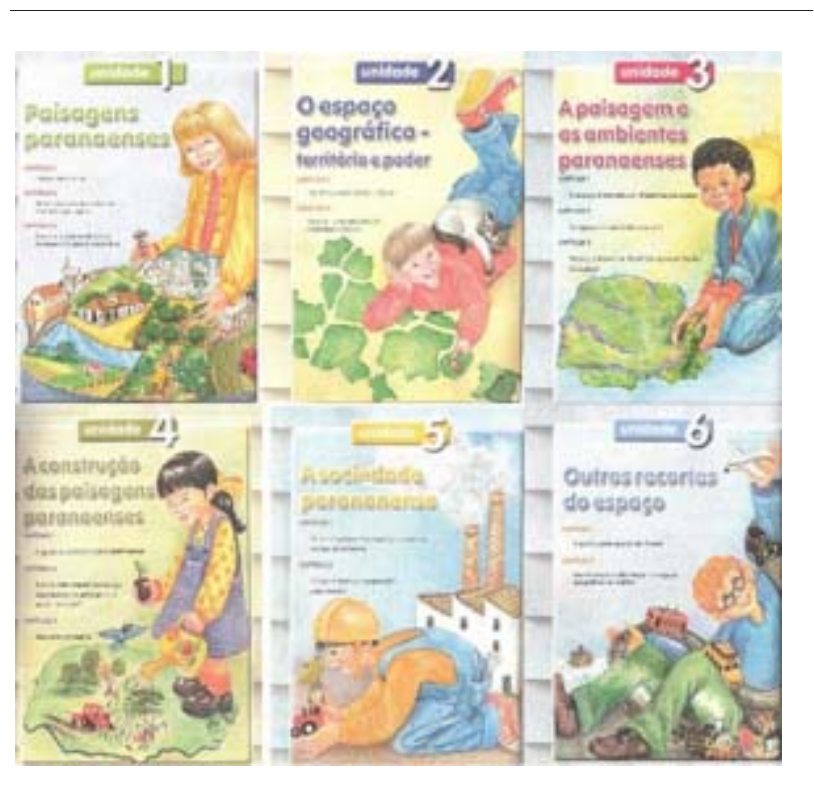

Fonte: Bley (2004).

Ainda explorando os personagens das capas de unidades, interpretamos que pode haver certa sequência temporal relacionado às aberturas. Enquanto o menino branco da unidade 2 (Figura 4) parece montar o mapa do Paraná, como se fosse um quebra-cabeça (podemos considerar que o menino branco tem o poder para a demarcação do território do estado, justificada pelo próprio título da unidade que acompanha a ilustração: "O espaço geográfico território e poder”), o menino negro da capa da unidade 3 (Figura 4) é responsável por fazer o preparo do solo - com as próprias mãos, uma maior proximidade do negro com a natureza. Segundo Ratts et al. (2006), podemos considerar esse um falso status positivo, já que o personagem está mais próximo aos instintos, espaço em que o negro consegue representação simbólica, como nas ilustrações relacionadas às danças e aos esportes. Os espaços onde o negro consegue representação tendem a ser espaços onde as relações raciais são horizontais (TELLES, 2003), ou seja, onde não ocorre disputa acirrada por poder.

$\mathrm{Na}$ capa da unidade 4, a personagem é uma menina amarela, usando um instrumento (um regador) e carregando uma muda de planta. Os meninos das unidades 5 e 6 brincam com veículos em miniaturas, após a consolidação do estado. Interpretamos essa sequência como uma cadeia de raciocínio que procura justificar ou defender determinada situação - no caso, como o final é o menino branco, ele está no topo da cadeia racionalizada: ela legitima ou defende a presença do branco como aquele que detém o conhecimento tecnológico, ao mesmo tempo em que coloca o amarelo e, sobretudo, o negro, tecnologicamente, em condição de atraso. Ao mesmo tempo, essa cadeia de raciocínio pode atuar unificando os personagens das 
capas das unidades em torno do mapa paranaense e das paisagens do estado - o mapa e as paisagens simbolizam a unidade do povo.

\section{Considerações finais}

Os livros didáticos que tratam da Geografia do estado do Paraná aprovados pelo PNLD/2007, em suas ilustrações, pouco apresentam personagens negros. A imensa maioria de personagens brancos nos livros indica que eles são considerados os representantes máximos do povo paranaense, restando, ao negro, o papel de outro nessa sociedade. Os brancos são considerados, então, os ocupantes do território paranaense por direito.

A apresentação de negros em menor número, em grandes grupos de personagens, assim com os papéis sociais que ocupa nos livros revela que eles tendem a ser tratados como objetos, "passificados". As vinhetas, relacionadas à construção cientifica do saber em Geografia, não apresentam o negro, o que indica que esse está distante de ser considerado capaz de fazer parte da construção do saber científico, ou seja, distante desse espaço social.

A naturalização do branco na condição de representante da humanidade e do saber científico ocidental nas produções simbólicas dos livros didáticos provavelmente contribui para manter e construir relações de dominação existentes entre brancos e negros na sociedade paranaense. Por outro lado, não encontramos personagens negros representados em espaços de miséria e pobreza, ainda que os livros pouco discutissem esses temas. Pode ser que essa ausência de negros em espaço de pobreza seja uma tentativa de fugir aos estereótipos explícitos, o que, provavelmente, pode ser, em parte, resultado das denúncias sobre racismo nos livros didáticos e da Lei 10.639/03 (BRASIL, 2003).

A pesquisa indicou que as práticas racistas persistem no discurso dos livros didáticos de geografia do Paraná, de maneira mais implícita, sem recorrer a estereótipos do negro folclorizado, como o descrito por Rodrigues e Cardoso (2010), mas hierarquizando as posições de negros e brancos, concedendo, ao branco, o privilégio de construção do saber científico. É preciso que a avaliação dos livros, então, também atente a formas implícitas de hierarquização racial presentes nas obras.

\section{Referências}

APPLE, M. W. Trabalho docente e textos: economia política das relações de classe e de gênero em educação. Porto Alegre: Artes Médicas, 1995.

BARDIN, L. Análise de conteúdo. Lisboa: Edições 70, 1985.

BLEY, B. Aprendendo a geografia do Paraná: geografia regional $3^{a}$ série. Curitiba: Positivo, 2004. 
Espaços de negros e brancos em livros ...

BOULOS JÚNIOR, A. Imagens da África, dos africanos e seus descendentes em coleções de didáticos de história aprovadas no PNLD de 2004. 2008. 204 f. Tese (Doutorado em Educação) - Pontifícia Universidade Católica de São Paulo, São Paulo, 2008.

BRASIL. Ministério da Educação. Guia do livro didático 2007: geografia séries/anos iniciais do ensino fundamental. Brasília, 2006. (Programa Nacional do Livro Didático). Disponível em: <ftp://ftp.fnde.gov.br/web/livro_didatico/guias_pnld_2007_ geografia.pdf>. Acesso em: 17 out. 2013.

Presidência da República. Lei $\mathbf{n}^{\mathbf{0}} \mathbf{1 0 . 6 3 9}$, de 9 de janeiro de 2003. Altera a Lei n ${ }^{\circ}$ 9.394, de 20 de dezembro de 1996, que estabelece as diretrizes e bases da educação nacional, para incluir no currículo oficial da rede de ensino a obrigatoriedade da temática "História e Cultura Afro-Brasileira", e dá outras providências. Disponível em: <http:// www.planalto.gov.br/ccivil_03/leis/2003/110.639.htm>. Acesso em: 21 out. 2013.

COSTA, R. L. S.; DUTRA, D. F. A lei 10639/2003 e o ensino de geografia: representação dos negros e África nos livros didáticos. In: ENCONTRO NACIONAL DE PRÁTICA DE ENSINO EM GEOGRAFIA, 10., 2009, Porto Alegre. Anais... Porto Alegre: UFRGS, 2009. Disponível em: < http://www.agb.org.br/XENPEG/artigos/eixo3.htm> Acesso em: 18 nov. 2010. p. 1-15.

FERRETTI, E. R.; PAZZINATO, K. R. C.; RENK, V. E. Paraná: sua gente e suas paisagens: geografia do estado do Paraná para o ensino fundamental. Curitiba: Base, 2004.

GIROUX, H. A. Por uma pedagogia e política da braquidade. Cadernos de Pesquisa, Pelotas, n. 107, p. 97-132, jul.1999.

GUIMARÃES, A. S. A. Racismo e anti-racismo no Brasil. 1997. 2 v. Tese (Livre Docência) - Faculdade de Filosofia, Letras e Ciências e Humanas, Universidade de São Paulo, São Paulo, 1997.

LEITE, D. M. Preconceito racial e patriotismo em seis livros didáticos primários brasileiros. In: LEITE, R. M. (Org.). Psicologia diferencial e estudos em educação. São Paulo: Editora Unesp, 2008. p. 209-237.

MANTOVANI, K. P. O Programa Nacional do Livro Didático - PNLD: impactos na qualidade do ensino público. 2009. 126 f. Dissertação (Mestrado em Geografia) - Faculdade de Filosofia, Letras e Ciências Humanas, Universidade de São Paulo, São Paulo, 2009.

PAIXÃO, M.; CARVANO, L. M. (Org.). Relatório anual das desigualdades raciais no Brasil, 2007-2008. Rio de Janeiro: Garamond, 2008.

PAIXÃO, M. et al. (Org.). Relatório anual das desigualdades raciais no Brasil, 2009-2010. Rio de Janeiro: Garamond, 2010. 
PERES, S. O PNLD brasileiro como estratégia de controle social sobre o ensino de história no contexto do Mercosul: entre o risco e a necessidade. In: REUNIÃO ANUAL DA ASSOCIAÇÃO NACIONAL DE PÓS-GRADUAÇÃO E PESQUISA EM EDUCAÇÃO. 25., 2002, Caxambu. Anais... Caxambu: ANPEd, 2002. Disponível em: <http:// www.anped.org.br/reunioes/25/tp251.htm\#gt13> Acesso em: 17 nov. 2010.

PESQUISA Nacional por Amostra de Domić́lios. Rio de Janeiro: IBGE, 2007.

RATTS, A. J. P. et al. Representações da África e da população negra nos livros didáticos de geografia. Revista da Casa da Geografia de Sobral, Sobral, v. 8, n. 1, p. 45-59, 2006.

RODRIGUES, M. A. C. N.; CARDOSO, E. A. A desconstrução do papel social do negro presente nas imagens e representações no livro didático de história e geografia. In: SEMINÁRIO NACIONAL DE ESTUDOS DE HISTÓRIA E CULTURAS AFRO-BRASILEIRAS E INDÍGENAS, 3., 2010, Campina Grande. Anais... Campina Grande: UFPB, 2010.

ROSEMBERG, F.; BAZILLI, C.; SILVA, P. V. B. Racismo em livros didáticos brasileiros e seu combate: uma revisão da literatura. Educação e Pesquisa, São Paulo, v. 29, n. 1, p. 125-146, 2003.

SANTOS, J. R. O que é racismo. São Paulo: Brasiliense, 1984.

SANTOS, R. E. O ensino de geografia do Brasil e as relações raciais: reflexões a partir da lei 10.639. In: SANTOS, R. E. (Org). Diversidade, espaço e relações étnico-raciais: o negro na geografia do Brasil. Belo Horizonte: Autêntica, 2007. p.21-40.

SILVA, P. V. B. Relações raciais em livros didáticos de língua portuguesa. 2005. $243 f$. Tese (Doutorado em Psicologia Social) - Pontifícia Universidade Católica de São Paulo, São Paulo, 2005.

SPSS Statistics for Windows. Version 17.0. Chicago: SPSS Inc., 2008.

TELLES, E. Racismo à brasileira: uma nova perspectiva sociológica. Rio de Janeiro: Relume Dumará, 2003.

THOMPSON, J. B. Ideologia e cultura moderna: teoria social crítica na era dos meios de comunicação de massa. Petrópolis: Vozes, 1995.

TONINI, I. M. Identidades étnicas: a produção de seus significados no livro didático de geografia. In: REUNIÃO ANUAL DA ASSOCIAÇÃO NACIONAL DE PÓSGRADUAÇÃO E PESQUISA EM EDUCAÇÃO, 24., 2001, Caxambu. Anais... Caxambu: ANPEd, 2001. Disponível em: < http://www.anped.org.br/reunioes/24/tp1.htm\#gt13>. Acesso em: 17 nov. 2010.

Artigo recebido em 14/01/13. Aceito em 28/08/13. 